Egyptian Journal of Aquatic Biology \& Fisheries

Zoology Department, Faculty of Science,

Ain Shams University, Cairo, Egypt.

ISSN $1110-6131$

Vol. 25(2): 63 - 74 (2021)

www.ejabf.journals.ekb.eg

\title{
Effect of extenders, cryoprotectants, and freezing methods on sperm quality and fertilisation rate of the European sea bass (Dicentrarchus labrax)
}

\author{
Magdy R. Badr ${ }^{1}$, Zaher M. Rawash ${ }^{1}$, Hany M. Hassan ${ }^{1}$, Mohamed E. Elaraby ${ }^{3}$, \\ Mohamed A. Amer ${ }^{2}$, Kareem M. Ahmed ${ }^{2 *}$ \\ 1. Animal Reproduction Research Institute (ARRI), Haram- Giza, Egypt. \\ 2. Animal Production Department, Faculty of Agriculture, Ain Shams University, Cairo, Egypt. \\ 3. General Authority of Fish Resources Development (GAFRD), Cairo, Egypt. \\ *Corresponding Author: kareem_ahmed@agr.asu.edu.eg
}

\begin{abstract}
ARTICLE INFO
Article History:

Received: Feb. 16, 2021

Accepted: March 14, 2021

Online: March 21, 2021

Keywords:

Dicentrarchus labrax,

cryoprotectant,

Sea bass,

semen extender,

Semen freezing methods,

Sperm quality

\section{ABSTRACT}

Fish semen cryopreservation is a valuable technique to sustain good quality sperm for fertilization, facilitating threatened species conservation and broodstock genetic development. The present investigation aimed to develop suitable standardized protocols to cryopreserve sea bass (Dicentrarchus labrax) semen. Thus, four experiments were conducted to determine the most effective extender (egg-yolk citrate, urea-egg-yolk, and $0.9 \% \mathrm{NaCl}$ ), cryoprotectant (DMSO, glycerol, ethylene glycol "EG", and methanol), sperm/cryodiluent dilution ratio $(1: 2,1: 4,1: 10$, and 1:20) and equilibration time $(0,5,15$, or $30 \mathrm{~min})$ to maintain the sperm content after cryopreservation. The consistency of post-thaw semen was assessed, with motility percentage, motility duration, and fertilization rate all being taken into account. When sperms were thawed, the consistency was at its best, especially when sperm was diluted with a ratio of 1:20 with egg-yolk citrate extender containing $10 \%$ DMSO, with a 15 -min equilibration period before cryopreservation. Sea bass sperm cryopreserved using this protocol exhibited fertilisation rates, class motility, and motility duration close to fresh semen. Thus, the cryopreservation method developed in the present investigation proved to be an efficient and effective approach to augment the cryosurvival of sea bass spermatozoa.
\end{abstract}

\section{INTRODUCTION}

The European sea bass Dicentrarchus labrax is a valuable commercial commodity in the Mediterranean Sea. In 2016, the global aquaculture production of seabass was 191,000 tonnes; 24,000 tonnes were produced mainly by the Egyptian mariculture sector (EUMOFA, 2019). The gilthead seabream (Sparus aurata) and European sea bass are the most common marine species in Egyptian mariculture farms, representing 1.92\% (29,994 tonnes) and $1.60 \%$ (24,914 tonnes) of national production, respectively (GAFRD, 2018). Due to the limited number of marine hatcheries and the seasonality of reproduction, the application of cryopreservation techniques is necessary to increase marine hatchery 
productivity. Additionally, the development of artificial breeding techniques would reduce the pressure on wild stocks created by the increasing demand for larvae.

The effectiveness of cryopreservation of marine fish sperm was determined by both the built-in sperm quality, as well as external considerations, such as mixing the semen with urine at the time of collection (Dreanno et al., 1998) and the time span between sperm collection/dilution and cryopreservation (Sansone $\boldsymbol{e t}$ al., 2002). To extend sperm viability before freezing, extenders are added to fish semen. Salty and sugary (1\%-10\%) solutions are the common extender types used for freezing marine fish semen. Both types of extenders immobilise spermatozoa to limit energy consumption to basic metabolism (Kopeika et al., 2007). Due to the elevated cholesterol/phospholipid ratio, the presence of phosphatidylcholine in the spermatozoa membrane, and the high adenosine triphosphate (ATP) content immediately after spermiation, marine fish milt is thought to be more freeze tolerant (Drokin, 1993).

In addition, the survivability of spermatozoa during the freezing procedure can be enhanced using cryoprotectants. Cryoprotectants maintain sperm quality throughout the freezing process by reducing water binding with crystal formations, structuring uniform crystals, and electrolyte binding. These attributes limit the creation of concentrated residual solutions; thus, decreasing the freezing point (Linhart et al., 2009). Two groups of cryoprotectants are used in fish sperm cryopreservation, the permeable group [ethylene glycol (EG), propylene glycol (PG), glycerol (G), dimethylacetamide (DMA), dimethyl sulfoxide (DMSO), methanol (M)] and the non-permeable group (glucose, sucrose, eggyolk). DMSO is the most commonly used cryoprotectant due to its quick penetration and interaction with spermatozoa phospholipid layer properties (Suquet et al., 2000; Gwo, 2011). The concentrations of cryoprotectants normally vary from 5 to 12 percent $(\mathrm{v} / \mathrm{v})$ per semen sample (Kopeika et al., 2007). Higher concentrations could provide better cell defence., but cryoprotectant toxicity must also be considered (Stoss, 1983; Balamurugan \& Munuswamy, 2017). Additionally, the medium and sperm dilution rates are equally important and sensitive to species; typically, one volume of sperm is mixed with one volume of medium (Boryshpolets et al., 2011).

The achievement of cryopreservation for semen sampling from marine fish in field operations, which requires handling many samples and transportation before freezing, is unreliable and must be improved. The quality of fish sperm is better judged by its potential to fertilise (Fauvel et al., 2012). However, due to the multifactorial determinism of fertilisation success, parameters such as motility may also indicate variances in sperm quality. Fertilisation success depends on egg quality, fertilisation environment (Fauvel \& Suquet, 2008), sperm condition and sperm-to-egg ratio (Cabrita et al., 2009). As a general characteristic, fish sperm is immotile in the genital tract; sperm motility is caused by changes in the ejaculation environment (Alavi et al., 2004) or later. The motility normally affects all accompanying spermatozoa but, under laboratory setting, a double dilution step is recommended for motility testing (Billard \& Cosson, 1992). The energy 
content of the cells and the membrane ability to make ionic transfers, which activate the enzymatic cascade responsible for motility, are closely linked to the activation and length of sperm motility (Boryshpolets et al., 2011). The extreme increase in osmolarity caused by spermiation cause sperm motility in marine fish, while osmolality or ionic composition triggers sperm movement in freshwater fish (Morisawa \& Morisawa, 1988). The goal of our research was to develop proper freezing and cryopreservation standardized protocols to cryopreserve seabass spermatozoa.

\section{MATERIALS AND METHODS}

This investigation was conducted in northern Egypt at Kilo 21 Hatchery in Agami, Alexandria. Six male sea bass were randomly selected for milt sampling during the reproductive period, which runs from January to February.

\subsection{Experimental design}

Four experiments have been undertaken to develop and standardise protocols for the cryopreservation of seabass sperm. Suitable extenders (egg-yolk citrate, urea-eggyolk, and $0.9 \% \mathrm{NaCl}$ ) were determined by the first experiment and suitable cryoprotectants (DMSO, glycerol, EG, and methanol) by the second experiment. The third experiment was conducted to determine the suitable sperm/cryodiluent ratio $(1: 2$, $1: 4,1: 10$, and 1:20) on a v/v basis. The fourth experiment compared among equilibration times ( 0 - no equilibration, 5,15 , or $30 \mathrm{~min}$ ) to determine the best equilibration time. The third and fourth experiments were adopted and modified from Zilli et al. (2005) and Marco-Jiménez et al. (2006).

\subsection{Fish and milt collection}

The seabass broodstock tanks were maintained at $20{ }^{\circ} \mathrm{C}, 38$ salinity, $5.7 \mathrm{mg} \cdot \mathrm{l}^{-1}$ minimum oxygen concentration. The broodstock tank water column was reduced before collection to easily capture the brooders. Mature males with desired phenotypic characteristics (three years old, length $25-30 \mathrm{~cm}$, weight 200-250g) were selected and anaesthetised using $70 \mathrm{mgl}^{-1}$ tricaine methanesulfonate (MS-222), and spawning was induced by injecting LHRHa $0.5 \mathrm{ml} \mathrm{kg}^{-1}$ to collect milt. The urogenital area was cleaned with absorbent paper towels to avoid sperm contamination. Milt was collected in clean dry $2.0 \mathrm{ml}$ centrifuge tubes by applying gentle manual pressure to the testes and sperm ducts. To avoid quality degradation during processing, the collected milt samples were tagged and sent to the laboratory in a dark cold thermos $\left(0-4{ }^{\circ} \mathrm{C}\right)$.

\subsection{Evaluation of sperm quality}

The collected semen was measured using a scaled plastic tube; the amount collected ranged from 0.5 to $2 \mathrm{ml}$. Semen was visually inspected for hematospermia and pyospermia, and semen $\mathrm{pH}$ was assessed using indicator strips. Fresh semen motility was determined by microscopic examination at room temperature. A drop of milt was mounted to a slide and activation solution $(50 \mu \mathrm{l}$ of seawater) was added in a ratio of 
1:10, mixed, covered and inspected. Only semen samples containing more than $90 \%$ motile sperm cells were used for cryopreservation.

\subsection{Cryodiluents and freezing}

Sperm samples were diluted by adding extenders and cryoprotectants to the milt sample at predetermined ratios. Three extenders (egg-yolk citrate, urea-egg-yolk, and $0.9 \% \mathrm{NaCl}$ ) and four cryoprotectants (DMSO, glycerol, ethylene glycol and methanol) were combined to make twelve cryodiluents. Cryodiluents were prepared by mixing $10 \%$ cryoprotectant to $90 \%$ extender by volume. Before dilution, the milt and the cryodiluents were stored on ice.

\subsubsection{Dilution and preparation of milt for cooling}

To determine the suitable dilution ratio, twelve were tested at four dilution ratios. The collected milt was diluted in four different amounts for each of the cryodiluents( $1: 2$, 1:4, 1:10, and 1:20 milt/cryodiluent).

\subsubsection{Equilibration, filling and sealing of straws}

The diluted milt was equilibrated for $0 \mathrm{~min}$ (no equilibration), $5 \mathrm{~min}, 10 \mathrm{~min}$ or 30 min at room temperature. Milt samples were cryopreserved in 0.5-ml straws, and the free end of the straw was sealed using polyvinyl chloride powder. The straws were then placed in the cryochamber and cooling was initiated. The milt was cooled from $20{ }^{\circ} \mathrm{C}$ to $-4{ }^{\circ} \mathrm{C}$ at a rate of $4{ }^{\circ} \mathrm{C}$ per minute, then from $-4{ }^{\circ} \mathrm{C}$ to $-80{ }^{\circ} \mathrm{C}$ at a rate of $10{ }^{\circ} \mathrm{C}$ per minute. The straws were frozen $6 \mathrm{~cm}$ above the liquid nitrogen level for $15 \mathrm{~min}$, and were stored in liquid nitrogen $\left(-196^{\circ} \mathrm{C}\right)$.

\subsubsection{Post-thawing motility assessment}

The straws were removed from the liquid nitrogen tank and thawed in a $20{ }^{\circ} \mathrm{C}$ water bath for 1 min (Marco-Jiménez et al., 2006). A $5 \mu \mathrm{l}$ aliquot of the thawed milt sample was placed on a glass slide and activated with conditioned water. Motility was assessed using a phase-contrast microscope.

\subsubsection{Insemination and fertilisation}

The post-thaw examinations revealed that sperm motility was not effectively maintained using the $0.9 \% \mathrm{NaCl}$ and urea-egg-yolk extenders, so samples containing these extenders were not utilized in the fertilisation stage. The fertilisation step began after the collection of eggs from female seabass. Eggs from four females were gathered and divided into 5g samples (roughly 5000 eggs). Experimental and control groups were formed for the fertilisation stage. Fresh semen collected from three males was pooled and diluted (1:10) using sperm saline solution. Frozen-thawed semen was diluted (1:3) using saline solution. Eggs $(5 \mathrm{~g})$ were placed in 50-mL plastic tubes, and semen was added for fertilisation. After $10-15 \mathrm{~s}$ of delicate mixing, activation solution (3:1 activation solution/eggs ratio) was applied to activate the spermatozoa and swell the eggs. The activation solution temperature was maintained at the same level as the eggs, water in the tank, and semen (approximately $18{ }^{\circ} \mathrm{C}$ ). To avoid temperature fluctuations and osmotic shock, the mixture was carefully and steadily moved into incubators with 500-m mesh 
three minutes after the activation solution was added. A dissecting microscope was used to measure the fertilisation rate of 200 randomly chosen eggs; fertilisation was expected when the egg cleaved to the four-cell level.

\subsubsection{Statistical analysis}

Data were analysed using two-and three-factors ANOVA. Duncan's Multiple Range Test was used to isolate means after significant findings (at $P<0.05$ ). SPSS version 20 was used for all statistical analysis (SPSS, Richmond, VA, USA).

\section{RESULTS}

The cryopreservation of seabass semen with egg-yolk citrate extender maintained the post-thawing motility and motility duration $(78.33 \pm 10.15 \%$ and $33.66 \pm 4.41 \mathrm{~s}$, respectively) to levels comparable to fresh semen $(86.67 \pm 4.41 \%$ and $43.33 \pm 6.01 \mathrm{~s}$, respectively); no significant differences were detected (Table 1). However, cryopreservation with $0.9 \% \mathrm{NaCl}$ extender significantly $(P<0.05)$ reduced post-thawing motility and motility duration of seabass semen $(28.33 \pm 9.28 \%$ and $5.67 \pm 1.76 \mathrm{~s}$, respectively) compared to fresh semen and the two other extenders.

Table 1. Effect of three extenders on seabass semen motility after cryopreservation compared to fresh semen (means $\pm \mathrm{SE}$ )

\begin{tabular}{lcc}
\hline & Post-thawing motility $(\%)$ & Motility duration $(\mathbf{s})$ \\
\hline Fresh semen & $86.67 \pm 4.41^{\mathrm{a}}$ & $43.33 \pm 6.01^{\mathrm{a}}$ \\
Egg-yolk citrate & $78.33 \pm 10.15^{\mathrm{ab}}$ & $33.66 \pm 4.41^{\mathrm{a}}$ \\
Urea-egg-yolk & $55.00 \pm 7.64^{\mathrm{b}}$ & $16.67 \pm 4.42^{\mathrm{a}}$ \\
$\mathbf{0 . 9 \%} \mathbf{~ N a C l}$ & $28.33 \pm 9.28^{\mathrm{c}}$ & $5.67 \pm 1.76^{\mathrm{b}}$ \\
\hline
\end{tabular}

Values with different superscript/s within each column are significantly different $(P$ $<0.05)$

The data presented in Table $(2)$ show that there was a significant $(P<0.05)$ superiority in post-thawing motility and motility duration of sea bass semen cryopreserved with egg-yolk citrate containing 10\% DMSO $(81.67 \pm 4.42 \%$ and $33.33 \pm$ $4.42 \mathrm{~s}$, respectively) compared to egg-yolk citrate containing $10 \%$ glycerol $(25.00 \pm$ $5.78 \%$ and $11.33 \pm 1.76 \mathrm{~s}$, respectively) or $10 \% \mathrm{EG}(55.00 \pm 2.89 \%$ and $21.67 \pm 2.02 \mathrm{~s}$, respectively). The results demonstrate that the addition of glycerol to the freezing extender drastically reduced marine fish semen quality during cryopreservation. 
Table 2. Effect of four cryoprotectants on seabass semen motility after cryopreservation using egg-yolk citrate extender (mean \pm SE)

\begin{tabular}{lcc}
\hline Cryoprotectants & $\begin{array}{c}\text { Post-thawing motility } \\
(\boldsymbol{\%})\end{array}$ & Motility duration (s) \\
\hline DMSO & $81.67 \pm 4.42^{\mathrm{a}}$ & $33.33 \pm 4.42^{\mathrm{a}}$ \\
Glycerol & $25.00 \pm 5.78^{\mathrm{c}}$ & $11.33 \pm 1.76^{\mathrm{c}}$ \\
Ethylene glycol & $55.00 \pm 2.89^{\mathrm{b}}$ & $21.67 \pm 2.02^{\mathrm{b}}$ \\
Methanol & $73.33 \pm 10.15^{\mathrm{ab}}$ & $28.66 \pm 2.41^{\mathrm{ab}}$ \\
\hline
\end{tabular}

Values with different superscript/s within each column are significantly different $(P<0.05)$

The post-thawing motility and motility duration of seabass semen in a 1:20 dilution with egg-yolk citrate extender containing 10\% DMSO $(83.33 \pm 4.42 \%$ and $34.33 \pm 1.20 \mathrm{~s}$, respectively) were significantly higher $(P<0.05)$ than those diluted with egg-yolk citrate containing 10\% DMSO in ratios of 1:2, 1:4, and 1:10 (Table 3).

Table 3. Effect of milt/cryodiluent ratios on seabass semen motility after cryopreservation using egg-yolk citrate containing $10 \%$ DMSO (mean \pm SE)

\begin{tabular}{ccc}
\hline $\begin{array}{r}\text { Dilution ratio } \\
\text { (milt:cryodiluent) }\end{array}$ & $\begin{array}{c}\text { Post-thawing motility } \\
(\boldsymbol{\%})\end{array}$ & Motility duration (s) \\
\hline $\mathbf{1 : 2}$ & $31.67 \pm 8.83^{\mathrm{c}}$ & $5.33 \pm 1.53^{\mathrm{c}}$ \\
$\mathbf{1 : 4}$ & $43.33 \pm 4.42^{\mathrm{bc}}$ & $9.67 \pm 1.20^{\mathrm{c}}$ \\
$\mathbf{1 : 1 0}$ & $60.00 \pm 2.89^{\mathrm{b}}$ & $23.33 \pm 3.85^{\mathrm{b}}$ \\
$\mathbf{1 : 2 0}$ & $83.33 \pm 4.42^{\mathrm{a}}$ & $34.33 \pm 1.20^{\mathrm{a}}$ \\
\hline
\end{tabular}

Values with different superscript/s within each column are significantly different $(P$ $<0.05)$

A significant $(P<0.05)$ improvement in post-thawing motility and motility duration of seabass semen diluted 1:20 with egg-yolk citrate extender containing 10\% DMSO was observed with a 15-min equilibration period before cryopreservation $(83.33 \pm 7.27 \%$ and $42.67 \pm 6.94 \mathrm{~s}$, respectively) compared with those that were not equilibrated $(0 \mathrm{~min})$ or with a 30-min equilibration period (Table 4). These results indicate that the cryopreservation of seabass semen without equilibration time significantly reduced the semen quality post-thawing. 
Table 4. Effect of equilibration time on seabass semen motility after cryopreservation using 1:20 diluted semen with egg-yolk citrate containing 10\% DMSO (mean \pm SE)

\begin{tabular}{ccc}
\hline Equilibration time & Post-thawing motility (\%) & Motility duration (s) \\
\hline 0 $\mathbf{~ m i n}$ & $31.67 \pm 4.42^{\mathrm{c}}$ & $7.00 \pm 3.78^{\mathrm{c}}$ \\
$\mathbf{5}$ min & $66.67 \pm 6.02^{\mathrm{ab}}$ & $23.67 \pm 7.03^{\mathrm{bc}}$ \\
$\mathbf{1 5} \mathbf{~ m i n}$ & $83.33 \pm 7.27^{\mathrm{a}}$ & $42.67 \pm 6.94^{\mathrm{a}}$ \\
$\mathbf{3 0} \mathbf{~ m i n}$ & $56.67 \pm 6.02^{\mathrm{b}}$ & $14.00 \pm 1.73^{\mathrm{b}}$
\end{tabular}

Values with different superscript/s within each column are significantly different ( $P$ $<0.05)$

The results presented in Fig. (1) indicate that there was no statistical discernible difference $(P<0.05)$ in the fertilisation rate among seabass fresh semen and semen diluted 1:20 with egg-yolk citrate extender containing 10\% DMSO and equilibrated for 15 min before cryopreservation $(85.00 \pm 5.78 \%$ and $73.33 \pm 4.42$, respectively.

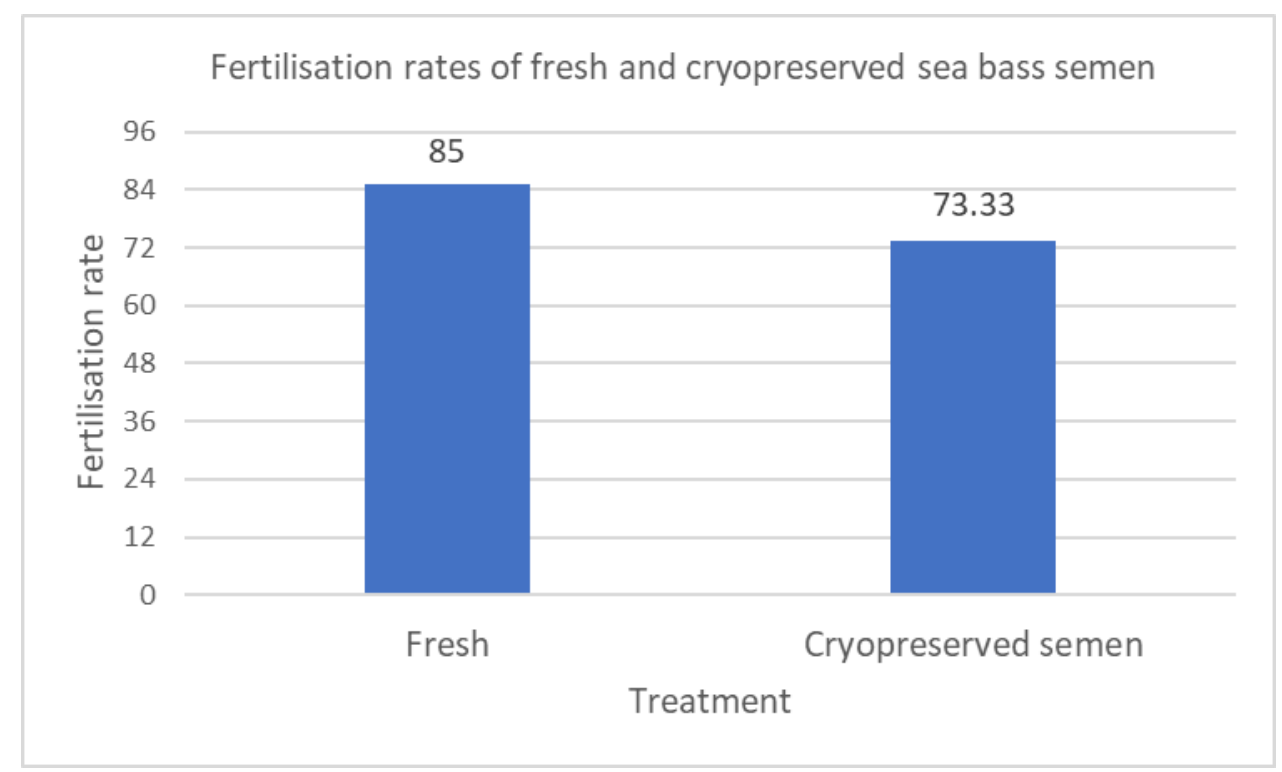

Fig. 1. Fertilisation rates obtained using fresh seabass semen and semen cryopreserved following the protocol developed in this study.

\section{DISCUSSION}

The current study showed significant differences in the efficacy of semen extenders and cryoprotectants. Additionally, an obvious variance in spermatozoa motility was observed with different equilibrium times and dilution ratios. Egg-yolk citrate was the most effective extender in terms of maintaining sperm motility. 
Among four cryoprotectants, DMSO resulted in the highest post-thaw spermatozoa motility and motility duration.

The cryoprotectants were maintained at a concentration of $10 \%(\mathrm{v} / \mathrm{v})$, which has been reported to be effective for many species (Withler, 1982). Our results are consistent with previous reports showing that egg-yolk citrate and urea-egg-yolk with $10 \%$ DMSO produced the best post-thaw motility and viability, whereas glycerol performed poorly in this study and with other species such as mrigal (Cirrhinus cirrhosis), common carp (Cyprinus carpio L.) and red seabream (Pagrus major) (Rao, 1989; Hua et al., 2012).

DMSO has been demonstrated to improve motile sperm velocity $10 \mathrm{~s}$ after activation when compared with fresh sperm. Additionally, post-thaw sperm frozen with 12-21\% DMSO showed similar straight trajectories. These outcomes could be associated with the rapid penetration of DMSO into spermatozoa and its interaction with the phospholipid membrane (Ogier de Baulny et al., 1996). Flow cytometric data analyses illustrate that a high percentage of turbot spermatozoa exhibited neither plasma membrane damage nor mitochondrial cryo-injuries in the presence of DMSO (Ogier de Baulny, 1997). The penetrative qualities of DMSO facilitate homeostasis of the intraand extra-cellular fluid concentration (Rao, 1989). Conversely, glycerol produced inferior post-thawing motility due to its slow penetration into the cell membrane (Harvey \& Ashwood-Smith, 1982). Moreover, extra-cellular cryoprotectant extenders such as egg-yolk contain low-density lipoproteins (LDL) that improve post-thaw motility and provide protection against cell membrane injuries during the cryopreservation process (Babiak et al., 2008). Low post-thaw motility was also observed using the inorganic extender $0.9 \% \mathrm{NaCl}$ with $10 \% \mathrm{DMSO}$. The lack of egg-yolk in the cryodiluent may be a reason for the poor results. The sperm/cryodiluent dilution ratio, in addition to the correct choice of extenders and cryoprotectants, is crucial for effective cryopreservation.

It is conceivable that the relationship between the concentration of sperm and the necessary amount of diluent could be a relationship that depends on the specificity of each species with probability of individual variations due to the modification of some environmental and/or administrative variables under captivity conditions. It was tested in this experiment four ratios of milt and cryodiluent (1:2, 1:4, 1:10, and 1:20), and found that the 1:20 ratio performed significantly better than the others. The dilution experiment was conducted with the best-performing extender, egg-yolk citrate. Increase in motility percentage nearly in parallel with the elevation of the dilution ratio was observed. The current findings are in line with those of Bergeron et al. (2002), who reported the best results with the highest dilution ratio when walleye sperm was diluted 1:5, 1:9 and 1:15. However, Sarder et al. (2009) found no significant effect on post-thaw motility when turbot sperm was diluted 1:1, 1:2, 1:4, and 1:9.

Regarding the effect of equilibration time on post-thawed semen quality, the current findings emphasise that equilibration seabass semen solution for 15 min before freezing yielded the best motility and viability. Ogier de Baulny (1997) observed that 
DMSO took 10 min to penetrate rainbow trout spermatozoa, although the fertilisation capability of frozen-thawed spermatozoa was the same with or without the equilibration period. With glycerol as a cryoprotective agent, the motility rate of frozen-thawed spermatozoa of bluefin tuna (Thunnus thynnus L.) rose with longer equilibration periods (30 min) compared with short ones (10 min), while the opposite has been reported using DMSO (Doi et al., 1982). Increased equilibration time might be needed for slowpenetrating glycerol. However, Jamieson (1991) reported that no equilibration period is required due to the small size of spermatozoa and rapid cryoprotectant penetration. Furthermore, The post-thaw motility of yellowfin sea bream spermatozoa was reduced when the equilibration time was increased from 5 to 60 minutes and the DMSO concentration was increased from $10 \%$ to $30 \%$. (Gwo 1994). When the equilibration time was longer than two minutes in sea bream, the fertilising capacity of frozen-thawed sperm with DMSO decreased (Billard 1978). A similar effect was observed after one hour in grey mullet (Chao et al., 1975). However, no effect on the fertility of frozenthawed spermatozoa was observed with equilibration times of 10 to 60 min (Tabata $\&$ Mizuta, 1997).

Finally, the current study examined the effect of cryopreservation on the fertilisation rate; cryopreserved seabass sperm exhibited similar fertilisation rates and motility duration compared to fresh semen. These results are supported by the findings of (Fauvel et al., 1998; Zilli et al., 2005) who illustrated that freezing and thawing reduced the sperm fertilisation ability by $10-23 \%$ compared to fresh semen.

\section{CONCLUSION}

The use of a 1:20 dilution of seabass sperm with egg-yolk citrate extender containing $10 \%$ DMSO, with a 15 min equilibration period before cryopreservation was most effective for maintaining fertilisation rate. This protocol effectively preserved seabass spermatozoa motility and egg fertilisation rate compared to fresh semen. The freezing method conceived in this study was found to be effective and could be used to augment the cryo-survival of the marine fish spermatozoa.

\section{REFERENCES}

Alavi, S.M.H.; Cosson, J.; Karami, M.; Abdoulhay, H. and Mojazi, A. B. (2004). Chemical composition and osmolality of seminal plasma of Acipenser persicus, their physiological relationship with sperm motility, Aquac. Res., 35: 38-43.

Babiak, I.; Bolla, S. and Ottesen, O. (2008). Suitable methods for cryop-reservation of semen from Atlantic halibut, Hippoglossus hipoglossus L. Aquac. Int., 16 (6) : 561-572. 
Bergeron, A.; Vandenberg, G.; Proulx, D. and Bailey, J. (2002). Comparison of extenders, dilution ratios and theophylline addition on the function of cryopreserved walleye semen. Theriogenology 57 : 1061- 1071.

Billard, R. (1978). Some data on gametes preservation and artificial insemination in teleost fish. Actes de colloques du CNEXO 8: 59-73.

Billard, R. and Cosson, M. P. (1992): Some problems related to the assessment of sperm motility in freshwater fish. J. Exp. Zool., 261: 122-131.

Boryshpolets, S.; Dzyuba, B.; Rodina, M.; Alavi, S. M. H.; Gela, D. and Linhart, O. (2011). Cryopreservation of sterlet (Acipenser ruthenus) spermatozoa using different cryoprotectans, J. Appl. Ichthyol., 27: 1147-1149.

Cabrita, E.; Engrola, S.; Conceição, L. E. C.; Pousão-- Ferreira, P. and Dinis, M. T. (2009). Successful cryopreservation of sperm from sex-- reversed dusky grouper, Epinephelus marginatus. Aquaculture, 287: 152- 157.

Chao, N. H.; Chen, H. P. and Liao, I. C. (1975). Study on cryogenic preservation of grey mullet sperm. Aquaculture, 5: 389-406.

Dreanno, C.; Suquet, M.; Desbruyères, E.; Cosson, J.; Le Delliou H. and Billard, R. (1998). Effect of urine on semen quality in turbot (Scophthalmus ma-ximus). Aquaculture, 169 : 247-262.

Doi, M.; Hoshino, T.; Taki, Y. and Ogasawara, Y. (1982). Activity of the sperm of the bluefin tuna thunnus thynnus under fresh and preserved conditions. Bull. Japan Soc. Sci. Fish, 48: 495-498.

Drokin, S. I. (1993). Phospholipid distribution and fatty acid composition of phosphatidylcholine and phosphatidylethanolamine in sperm of some freshwater and marine species of fish. Aquat. Living Resour, 6: 49-56.

EUMOFA (2019) The European Market Observatory for fisheries and aquaculture, PTAT Case Study - Seabass in the EU.

Fauvel, C.; Suquet, M.; Dreanno, C.; Zonno, V. and Menu, B., (1998). Cryopreservation of sea bass (Dicentrarchus labrax) spermatozoa in experimental and production simulating conditions. Aquat. Living Resour., 11 : 387-394.

Fauvel, C. and Suquet, M. (2008). Sperm cryopreservation: an actual tool for seabass (Dicentrarchus labrax) reproduction and breeding control in research and production. In: Methods in Reproductive Aquaculture: Marine and Freshwater Species. Biology Series. E. Cabrita, V. Robles, M. P. Herráez (Eds), CRCPress (Taylor and Francis group), pp. 437-442.

Fauvel, C.; Boryshpolets, S.; Cosson, J.; Wilson Leedy, J. G.; Labbé, C.; Haffray, P. and Suquet, M. (2012). Improvement of chilled seabass sperm conservation using a cell culture medium. J. Appl. Ichthyol., 28: 961-966.

GAFRD (2018). General Authority for Fish Resources Development. In: Fish Statistics Yearbook. Cairo, Egypt: Ministry of Agriculture and Land Reclamation. 
Gwo, J. C. (1994). Cryopreservation of yellowfin seabream (Acanthopagrus latus) spermatozoa (teleost, perciformes, sparidae). Theriogenology, 41: 989-1004.

Gwo J. C. (2011). Cryopreservation of sperm of some marine fishes. In: TR Tiersch, CC Green (eds) Cryopreservation in Aquatic Species, 2nd edn, World Aquaculture Society, Baton Rouge. Lousiana. pp. 459- 481.

Harvey, B. and Ashwood-Smith, M. J. (1982). Cryoprotectant penetration and supercooling in the Eggs of Salmonid fishes. Cryobiology, $19: 29-40$.

Hua, Q.; Zhong, Z.; Hong, S.; Yuan, D.; Shuang, Y. and Li, J., (2012). Marine Fish Sperm Cryopreservation and Quality Evaluation in Sperm Structure and Function, Current Frontiers in Cryopreservation. IntechOpen, Rijeka, p. Ch. 12., pp. 239-248. https://doi.org/10.5772/32870

Jamieson, G.M. (1991). Fish evolution and systematic: Evidence from spermatozoa, Cambridge University Press, Cambridge, 319pp.

Kopeika, E.; Kopeika, J. and Zhang, T. (2007). Cryopreservation of Fish Sperm. J.G. Day, eds, Methods in Molecular Biology, 2nd edition, Humana Press, New Jersey, United States., 203-219,

Linhart, O.; Rosenthal, H.; Cosson, J.; Noveiri, S.B. and Alipour, A. (2009). 5th International Symposium on Sturgeon, Workshop on sturgeon sperm cryopreservation, 16, Ramsar, Iran.

Marco-Jiménez, F.; Garzón, D. L.; Peñaranda, D. S.; Pérez, L.; Viudes-de-Castro, M. P.; Vicente, J. S.; Jover, M. and Asturiano, J. F. (2006). Cryopreservation of European eel (Anguilla anguilla) spermatozoa: Effect of dilution ratio, foetal bovine serum supplementation, and cryoprotectants. Cryobiology 53: 51-57. https://doi.org/10.1016/j.cryobiol.2006.03.011

Morisawa, S. and Morisawa, M. (1988). Induction of potential for sperm motility by bicarbonateand $\mathrm{pH}$ in rainbow trout and chum salmon. J. Exp. Biol.,136 : 13-22.

Ogier de Baulny, B. (1997). Cryoconservation du sperme de poissons. Evaluation des dommages cellulaires. Amélioration de la technique de congélation. Perméabilité membranaire aux cryoprotectants (Doctoral dissertation, Thesis) 129 pp.

Ogier de Baulny, B.; Le Vern Y.; Kerboeuf D.; Heydorff M. and Maisse G. (1996). Flow: cytometric analysis of plasma membrane damages of rainbow trout and turbot frozen. sperm. In : Proceedings of the commission C2, Refrigeration and Production. International Symposium (Froid et Aquaculture),p. 65-72, Bordeaux.

Rao, K. G. (1989). Cryopreservation of carp sperm. Fish Genetics in India, Today and Tomorrows Printers and Publishers, New Delhi, 193-198.

Sansone, G.; Fabbrocini, A., Ieropoli, S., Langellotti, A., Occidente, M. and Matassino, D. (2002). Effects of extender composition, cooling rate, and freezing on the motility of sea bass (Dicentrarchus labrax, L.) spermatozoa after thawing. Cryobiology, $44: 229-239$. 
Sarder, M. R. I.; Rafiquzzaman, S. M.; Sultana, R., and Islam, M. F. (2009). Cryopreservation of spermatozoa of Mrigal, Cirrhinus cirrhosus with a view to minimize inbreeding and hybridization. J. Bangladesh Agril. Univ., 7(1) : 211218.

Stoss, J., (1983). Fish gamete preservation and spermatozoan physiology. in: Fish physiology IX B, New york Academic Press, United States of America, pp. 305350.

Suquet, M.; Dreanno, C.; Fauvel, C.; Cosson, J. and Billard, R. (2000). Cryopreservation of sperm in marine fish. Aquac.Res; 31: 231-243.

Tabata, K. and Mizuta, A. (1997). Cryopreservation of sex reversed gynogenetic females sperm in hirame. Fisheries Science, $63: 482-483$.

Withler, F. C. and Lim, L. C. (1982). Preliminary observations of chilled and deepfrozen storage of grouper (Epinephelus tauvina) sperm. Aquaculture, 27: 389392.

Zilli, L.; Schiavone, R.; Zonno, V.; Rossano, R.; Storelli, C. and Vilella, S. (2005). Effect of cryopreservation on sea bass sperm proteins. Biol. Reprod., 72(5) : pp. 1262-1267. https://doi.org/10.1095/biolreprod.104.036202 